\title{
Emotional Intelligence and Caring Behavior Among Muslim Nurse: A Study in Religious-Based Hospital in Surabaya-Indonesia
}

\author{
Laily Hidayati, Fauzan Rifai, Lailatun Ni'mah \\ Faculty of Nursing, Universitas Airlangga, \\ Surabaya, Indonesia \\ Email address: laily-h@fkp.unair.ac.id
}

\begin{abstract}
Caring is an important aspect of nursing care implementation. It is referred to an ability to show an attention and feel empathy for others, especially for patients. Faith or religion give a contribution on performing behavior, attitudes and emotions of nurses in doing their job. In addition, emotional intelligence is mentioned as a critical success factor in the work by $80 \%$. But on the other hand, the system of nurse recruitment in Indonesia is still putting academic intelligence (GPA score) as the main requirement. This study aim to determine the relationship between emotional intelligence and caring behavior in Muslim nurse in a religious-based hospital in Surabaya, Indonesia. This was a cross sectional study. The population was all nurses in a surgical ward of a religious-based hospital in Surabaya. As many as 52 nurses participated as respondents based on inclusion and exclusion criteria. The dependent variable was emotional intelligence, and the independent variables are caring behavior. Data were analyzed using the Spearman rho test. The study showed that $57.7 \%$ of Muslim nurses performed good caring and $51.9 \%$ showed the ability to control emotions. The correlation between emotional intelligence and caring behavior in nurses showed $p$ value 0.000 and correlation coefficient $r=0.684$. Emotional intelligence showed a positive correlation with the caring behavior of Muslim nurse. It means that emotional intelligence could increase nurse caring behaviors. A religious-based hospital can support the development of emotional intelligence aspect through any kind program of emotional self-control for nurses.
\end{abstract}

Keywords- emotional intelligence, Muslim nurse, caring behavior, religious-based hospital

\section{INTRODUCTION}

Nurse is health worker that most often interact with patient. A good nurse should able to serve the patient with heart. Thus, nurse must have ability to care and pay attention to client other than intelectual, technical, and interpersonal skills that is reflected in caring behavior. [1]

Preliminary study conducted by interview in one of Islamic-based hospital in Surabaya-Indonesia. Most of nurses said that they already perform a caring behavior by provide a friendly act, but it could not optimal due to overload work. The others said that they could not always perform a caring behavior due to more focused on patient's care and treatment.
In daily working activities, nurse also should have emotional intelligence to control their negative emotion. Nurse that don't have a good emotional intelligence characterized by poor emotional attitude and not sensitive to others (patient and environment). Nursing care in Indonesia requires a nurse who has a good emotional intelligence to meet the needs of patients that includes biological, psychological, sociological and spiritual needs. [2]

Emotional intelligence and caring behavior are two important things in nursing care. However, until now the correlation of emotional intelligence and caring behavior of nurses has not been widely known, especially in Muslim nurses. This study aims to identify the correlation of emotional intelligence and caring behavior of Muslim nurses.

\section{METHOD}

This was a cross sectional study. The population was all nurses in the inpatient ward in one of Islamic-based hospital in Surabaya as many as 62 nurses. 52 muslim nurses taken as samples in this study refers to inclusion and exclusion criteria by using cluster sampling technique.

The variables were emotional intelligence and caring behavior of nurses. Caring Behaviors Inventory (CBI-24) which consists of 10 carative factors used to identify caring behavior, and the instrument used to identify emotional intelligence were adopted from Goleman's theory which divides the emotional intelligence into 5 aspects.[3] Spearman rho with $\alpha<0,05$ was used to analyze the correlation between variables.

\section{RESULT}

Most of respondents were female nurses $(78.8 \%)$ in age range of $40-50$ years old $(40.4 \%)$. The majority of respondents education are nursing diploma as much as $82.7 \%$, and 16 respondents $(30.8 \%)$ had a long working experience (10-15 years) (see Table I). Research revealed that 30 of 52 nurses performed good caring behavior, while the rest showed less in caring behavior. Most nurse had good carative factor in developing helping and trust relation, but less in instilling faith and hope (see table II). 
TABLE I. DISTRIBUTION OF DEMOGRAPHIC

\begin{tabular}{|l|l|}
\hline \multicolumn{1}{|c|}{ Components } & $\mathbf{n}(\%)$ \\
\hline Age $(\boldsymbol{y} . \boldsymbol{o})$ & $15(28,8)$ \\
\hline $20-30$ & $16(30,8)$ \\
\hline $30-40$ & $21(40,4)$ \\
\hline $40-50$ & $52(100)$ \\
\hline Total & $11(21,2)$ \\
\hline Gender & $41(78,8)$ \\
\hline Male & $52(100)$ \\
\hline Female & $43(82,7)$ \\
\hline Total & $9(17,3)$ \\
\hline Education & $52(100)$ \\
\hline Diploma & \\
\hline Bachelor & $12(23,1)$ \\
\hline Total & $15(28,8)$ \\
\hline Working Experience $($ year $)$ & $16(30,8)$ \\
\hline$<5$ & $4(7,7)$ \\
\hline $5-<10$ & $5(9,6)$ \\
\hline $10-<15$ & $52(100)$ \\
\hline $15-20$ &
\end{tabular}

TABLE II. DISTRIBUTION OF CARATIVE FACTORS

\begin{tabular}{|l|c|c|}
\hline \multicolumn{1}{|c|}{ Carative factors } & $\begin{array}{c}\text { Good } \\
(\boldsymbol{\%})\end{array}$ & Less (\%) \\
\hline Humanistic and altruistic & 59,62 & 40,38 \\
\hline Instilling faith and hope & 40.38 & 59,62 \\
\hline Cultivating sensitivity to one's self & 59.62 & 40,38 \\
\hline Developing helping and trust relation & 71.15 & 28,85 \\
\hline Expression of feeling, & 67.31 & 32,69 \\
\hline Using problem-solving caring process & 65.38 & 34,62 \\
\hline Promoting interpersonal teaching-learning & 51.92 & 48,08 \\
\hline Providing environtment, & 59.62 & 40,38 \\
\hline Assisting of human needs & 44.23 & 55,77 \\
\hline Allowing forces & 48.08 & 51,92 \\
\hline
\end{tabular}

Table III shows the respondents with a good emotional intelligence are 31 nurses $(59,6 \%)$, while the rest have less emotional intelligence. Furthermore, most of nurses seem to be able to control various emotional intelligence aspects. Self awareness was the best aspect of emotional intelligence shown by nurses, but they were still lack of empathy to the patient (see table IV).

Spearman rho test results showed a significant correlation between emotional intelligence and caring behavior with $\mathrm{p}=$ 0.000 and correlation coefficient $r=0.684$ (see table V). This indicates a positive and medium strength correlation between the variables of emotional intelligence and caring behavior, which means that the higher emotional intelligence then the better caring behavior is performed by nurse.

TABLE III. DISTRIBUTION OF NURSE'S EMOTIONAL INTELLIGENCE

\begin{tabular}{|l|c|}
\hline \multicolumn{1}{|c|}{ Emotional Intelligence } & $\mathbf{n}(\%)$ \\
\hline High & $31(59,6)$ \\
\hline Low & $21(40,4)$ \\
\hline Total & $52(100)$ \\
\hline
\end{tabular}

TABLE IV. DISTRIBUTION OF EMOTIONAL INTELLIGENCE ASPECTS

\begin{tabular}{|l|c|c|}
\hline \multicolumn{1}{|c|}{ Aspect } & Able to control (\%) & $\begin{array}{c}\text { Not able to } \\
\text { control (\%) }\end{array}$ \\
\hline Self awareness & 78,8 & 21,2 \\
\hline Self regulation & 57,7 & 42,3 \\
\hline Motivation & 63,5 & 36,5 \\
\hline Social skills & 57,7 & 42,3 \\
\hline Empathy & 53,3 & 46,7 \\
\hline
\end{tabular}

TABLE V. StATisticAl Result

\begin{tabular}{|l|c|c|c|}
\hline \multirow{2}{*}{ Caring behavior } & \multicolumn{2}{|c|}{ Emotional Intelligence } & \multirow{2}{*}{ Total } \\
\cline { 2 - 3 } & low & high & \\
\hline Less & 20 & 2 & 22 \\
\hline Good & 11 & 19 & 30 \\
\hline Total & 31 & 21 & 52 \\
\hline Spearman rho & \multicolumn{3}{|c|}{$\mathrm{p}=0,000$} \\
\cline { 2 - 3 } & $\mathrm{r}=0,684$ \\
\hline
\end{tabular}

\section{DISCUSSION}

The results showed that most nurses have high emotional intelligence but there are still some respondents who are less in controlling emotions. In addition, the highest score of emotional intelligence aspect is self awareness, meanwhile the lowest is empathy.

Reference [4] stated that emotional intelligence is the ability to understand and manage mood in order to keep rational thinking, and then perform various skills, both personal skills and interpersonal skills. Factors that affect emotional intelligence include gender, age, environment and educational background.

Respondents who has low emotional intelligence will have difficulties in work. Low emotional intelligence will affect selfcontrol ability and rational thinking. A better emotional intelligence, a better self emotional control will performed by nurse. Thus, patient will get a better service. But in fact, respondents showed a low performance in empathy, less in response and receiving complaints, and also less in ability to listening what the patient feels.

Reference [5] states empathy is a behavior that a nurse must have. Nurses in providing care to patients should be able to have a sense of empathy. The nurse must be able to feel what the patient feels and be able to understand the situation in the patient's point of view. A good empathy from nurse will provide satisfaction to the patients.

The research revealed that the lowest value of carative factor is on instilling faith and hope. Nurse not much gave motivation to the patient to recover from the illness. Furthermore, based on interviews with respondents, the behavior of instiling faith and hope is not good due to the high workload in the room, so that reduced duration of meeting with the patient. Therefore, nurse has difficulties to provide motivation and hope in the patient. Ideally, the motivation and hope of recovery by health professionals is meaningful for patients. This is because health workers are considered as someone who understands about his current health condition. [6] Reference [5] also stated that the nurses should be able to provide trust and hope for the patient in delivering nursing care. Thus, nurse can support the patient's belief system. 
The research showed there was a significant correlation between emotional intelligence and nurse's caring behavior positively, and in medium strenght level. These indicate that the higher the emotional intelligence, the better the nurse's caring behavior to the patient, and vice versa.

Caring behavior is closely related to empathy. Nurses who are able to behave caring will show empathy to the patient. The aspects of emotional intelligence is closely related to caring behavior in nurses. It is shown that aspects of emotional intelligence are an important component in shaping a professional nurse behavior. When the aspects of self-emotion, self-control, self-motivation, build a social relation and empathy are applied in the nursing process will lead to caring behavior to the patient.[5][6]

A high emotional intelligence will lead the nurse to unwittingly deliver a good caring behavior in the patient. For example, when nurses have a good social relationships then they able to communicate well to patients throughout developing truth and helping. In addition, when nurses do assisting of human needs, at the same time nurses have applied aspects of empathy to the patient.

\section{CONCLUSION}

Most muslim nurses had high emotional intelligence with the best aspect of emotional intelligence was self awareness, thus they showed good caring behavior to patients with best carative factors performed in developing helping and trust relationships. But, nurse caring behavior is still lacking on instilling faith and hope. The higher the emotional intelligence, the better the caring behavior. Nurses who have high emotional intelligence simultaneously show good caring behavior.

\section{RECOMMENDATION}

The hospital needs to consider the emotional intelligence factor in determining the policy for the nurse starting from recruitment. It is expected that intellectual intelligence (GPA score) is not the only major requirement but also includes emotional intelligence as a recruitment requirement. For nurses, the hospital can provide programs that can improve emotional intelligence as well as caring behavior of nurses. In addition, nursing education institutions also need to pay attention to the emotional intelligence and caring behavior of nursing students. Nursing education institutions can provide both curricular and extracurricular activities to improve the quality of nursing student outputs in caring and emotional intelligence. Further research can explore the effect of emotional intelligence on nurse caring behavior throughout any kind of intervention.

\section{REFERENCES}

[1] Nurul Qomariah, "Hubungan Kecerdasan Spiritual dengan Perilaku Caring Perawat pada Praktek Keperawatan di Ruang Rawat Inap Rumah Sakit Umum Pusat Haji Adam Malik Medan," Universitas Sumatera Utara, 2012.

[2] E. Rudyanto, "hubungan antara kecerdasan emosi dan kecerdasan spiritual dengan perilaku prososial pada perawat" Universitas Sebelas Maret Surakarta, 2010.

[3] D. Goleman, Emotional intelligence: [why it can matter more than IQ]. Bantam Books, 2006.

[4] L. R. Brody and J. A. Hall, Handbook of Emotions. Jakarta: EGC, 2007.

[5] J. Watson, Basic Nurse Caring Behavior. Jakarta: EGC, 2005.

[6] G. W. Stuart and M. T. Laraia, Principles and practice of psychiatric nursing. Mosby, 2001. 